\title{
Effectiveness of a brief school-based intervention on depression, anxiety, hyperactivity, and delinquency: a cluster randomized controlled trial
}

\author{
Ferry X. Goossens ${ }^{1,2} \cdot$ J. Lammers ${ }^{2} \cdot$ S. A. Onrust ${ }^{2} \cdot$ P. J. Conrod ${ }^{3}$ • \\ B. Orobio de Castro ${ }^{4} \cdot \mathrm{K}$. Monshouwer ${ }^{2,5}$
}

Received: 15 April 2015 / Accepted: 1 October 2015 / Published online: 12 October 2015

(C) Springer-Verlag Berlin Heidelberg 2015

\begin{abstract}
Problematic substance use and mental health problems often co-occur in adolescents. Effective schoolbased interventions that are brief and target multiple problems are promising in the field of health promotion. Preventure is a brief, school-based, selective preventive intervention, tailored to four personality profiles. Preventure has already proved effective on alcohol outcomes. Previous trials also reveal effects on several mental health outcomes, yet the evidence for these outcomes is limited. This study presents the results of the Dutch Preventure Trial, on a range of mental health outcomes. In a cluster RCT, including 699 high risk students (mean age 14 years), the intervention effects on mental health problems at 2, 6, and 12 months post intervention were tested in the total high risk population and in four specific personality groups. No significant intervention effects were found on 22 from the 24 tests. A positive intervention effect on anxiety was found in the anxiety sensitivity personality group at 12-month
\end{abstract}

Ferry X. Goossens

fgoossens@trimbos.nl

1 Trimbos Institute, Da Costakade 45, 3521, VS, Utrecht, The Netherlands

2 Trimbos Institute (Netherlands Institute of Mental Health and Addiction), P.O. Box 725, 3500, AS, Utrecht, The Netherlands

3 King's College London, Department of Psychological Medicine and Psychiatry, Institute of Psychiatry, 4 Windsor Walk, Denmark Hill, London SE5 8BB, UK

4 Department of Developmental Psychology, Utrecht University, P.O. Box 80140, 3508, TC, Utrecht, The Netherlands

5 Department of Interdisciplinary Social Science, Utrecht University, P.O. Box 80140, 3508, TC, Utrecht, The Netherlands follow-up, and a negative intervention effect on depression was found at 12-month follow-up in the negative thinking group. In post hoc growth curve analyses these effects were not found. This study found no convincing evidence for the effectiveness of Preventure in The Netherlands on mental health problems. This finding is not in line with the results of an earlier effectiveness study in the UK. This highlights the need for more research into the knowledge transfer model of interventions, to ensure that interventions are effective in a variety of circumstances.

Keywords Prevention - Intervention - Mental health · Adolescents

\section{Introduction}

Problematic substance use and mental health problems often co-occur in adolescents $[1,2]$. Studies have shown that an important part of this co-occurrence is explained by an overlap in risk factors [3]. Consequently, if these risk factors are causally related to both types of problems, effective preventive interventions targeting these risk factors are likely to reduce both substance use and mental health problems. Indeed, the school-based preventive interventions Preventure (counsellor based) and Adventure (teacher based), which were originally designed to prevent problematic alcohol use, have been shown to reduce not only risky drinking behaviors [4-7] and illicit drug use [8], but also a variety of mental health problems, including depression, anxiety, and a number of conduct disorders $[9,10]$.

Preventure and Adventure use a personality-targeted approach, based on the theory that personality is an important construct for understanding and preventing adolescents' alcohol use and abuse $[11,12]$. Both interventions 
discern four personality groups which receive interventions tailored to their personalities. These groups are high levels of negative thinking (NT), anxiety sensitivity (AS), sensation seeking (SS), and low levels of impulse control (IMP) [4]. These personality profiles have been identified as risk factors not only for substance abuse [11-18], but also for mental health problems like depression [19], anxiety [20], hyperactivity [21], and reckless behavior [22].

The effects of Preventure and Adventure on risky drinking behaviors have been studied extensively, mostly in Canadian and English samples of adolescents. Studies show a variety of 'condition' and 'condition $\mathrm{x}$ personality risk group' effects on risky drinking behaviors up to 24 months post intervention [4-7]. The effectiveness of Preventure on the primary alcohol-related outcomes is currently being tested in the Netherlands, using the same sample as used for this paper [23]. Binge drinking rates did not significantly differ between the intervention and control group at 12-month follow-up. Intention-to-treat analyses revealed no significant intervention effects on alcohol use and problem drinking at 12-month follow-up. However, post hoc latent-growth analyses revealed significant effects on the development of binge drinking, and binge drinking frequency [24].

To date, the effectiveness of Preventure on mental health problems has been studied in one trial in London [9]. This study among 423 students found a moderate intervention effect in the NT group on depression scores at 6-month follow-up and a similar effect in the AS group on panic attacks and truancy. A small intervention effect was found for shoplifting in the total high risk sample, as well as a moderate effect on this outcome in the IMP group. Yet, the results are limited to short-term mental health outcomes (i.e. at 6-month follow-up). Analysis of the secondary mental health outcomes of the Adventure program at 24-month follow-up showed that the intervention had generic effects in reducing depression and anxiety symptoms across all high risk youth, and personality-specific effects in reducing conduct problems in impulsive youth [10].

\section{Aims}

The aim of the present study was to test the effectiveness of Preventure in the Netherlands on a range of mental health outcomes at 2, 6, and 12 months post intervention. Based on previous finding $[9,10]$ and the theoretical underpinnings of Preventure, we expect a reduction of depression, anxiety, conduct problems, and hyperactivity rates, and delinquent risk taking behavior in the total intervention group as compared to the control group. Furthermore, we expect these effects to be moderated by personality, i.e. reductions in depression rates are strongest in the NT group, anxiety rates in the AS group, and hyperactivity rates, conduct problems, and delinquent risk-taking behavior in both the IMP and SS group.

Results of the primary alcohol-related outcomes are published yet [23] and the remaining (secondary) outcomes (drinking motives, smoking behavior, and marihuana consumption) will be published in future, separate journal articles.

\section{Method}

This study represents an analysis of the mental health secondary outcomes of a cluster randomized controlled trial with an intervention and a control condition, testing the intervention effects on mental health symptoms at 2,6 , and 12 months after the delivery of the intervention. The full study design is described in a study protocol [23] and the trial is registered in The Netherlands Trial Register (NTR1920).

\section{Participants}

A screening survey among all students attending grades 8 and 9 at each of the 15 participating schools was conducted to assess whether students were eligible to enter the trial. The inclusion criteria were defined as follows: (1) lifetime use of at least one glass of alcohol, (2) scoring at least one standard deviation above the sample mean on one of the four personality risk scales (AS, SS, NT, or IMP) of the Substance Use Risk Profile Scale (SURPS) [25], and (3) attending a school where at least five students per personality risk group were eligible and willing to be included in the intervention condition (in order to create workshops with sufficient interaction between students).

From the 4844 adolescents who completed the screening questionnaire, 1488 (31\%) met the first two inclusion criteria. If a student scored high on more than one subscale, he or she was assigned to the personality group in which he or she showed the largest statistical deviation with respect to the z-scores. Of those 1488 respondents, 713 (48\%) were willing to participate (active consent of both parent and student). However, 14 students were excluded because at their (intervention or control) school the number per personality risk group was too small (i.e. fewer than five students per workshop). This procedure resulted in 699 students (mean age at baseline 14 years) (see Fig. 1).

\section{Consent}

Parents were informed of the study (screening and intervention) through a letter sent by the school to the home 
Fig. 1 Participant flowchart

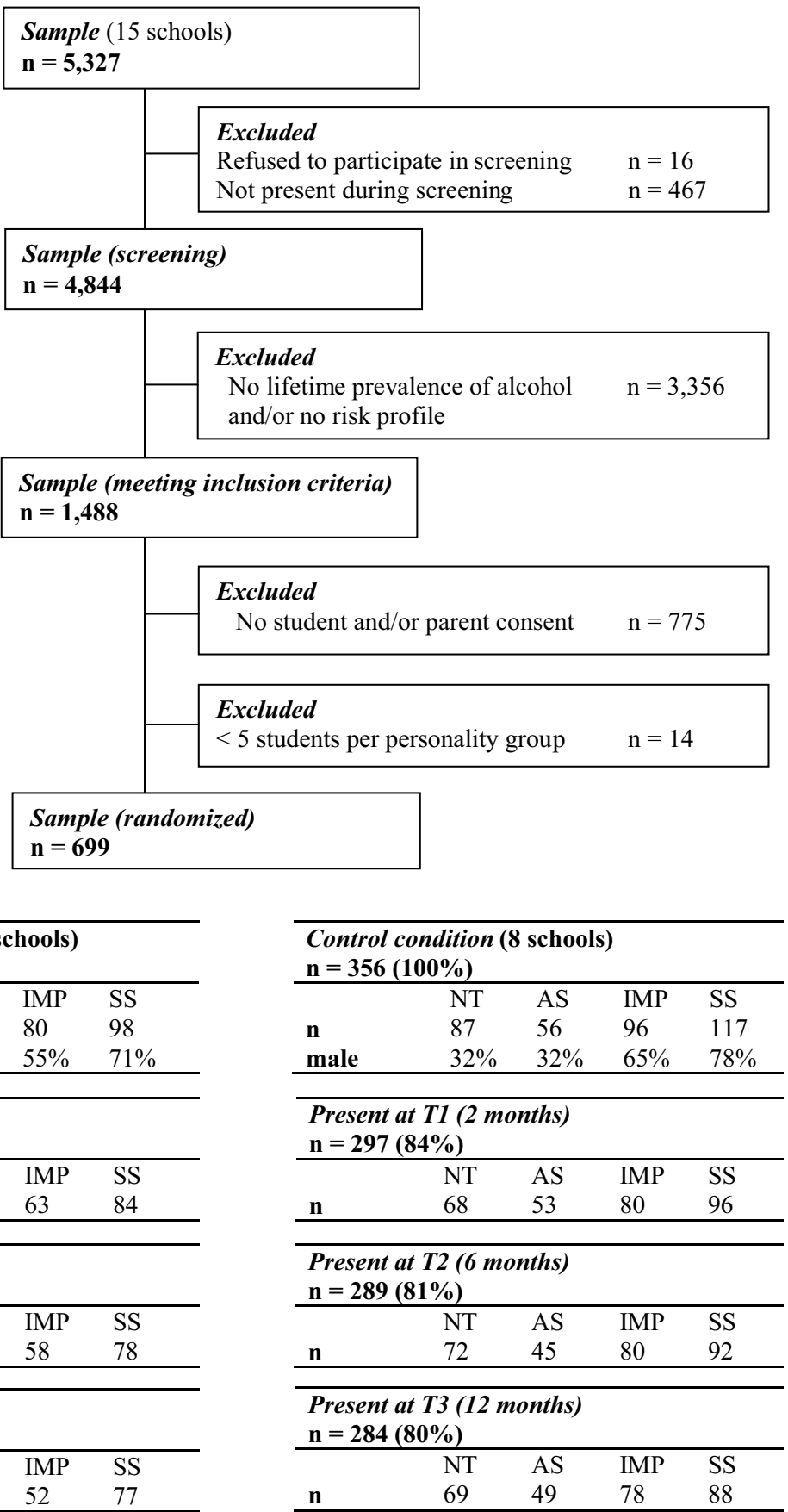

address asking them to contact the researchers by phone or e-mail if they did not wish their child to participate in the study (passive informed consent). Parents were told that the intervention was a coping-skill training designed to reduce adolescent risk taking, with alcohol abuse as an example. To assure participants' confidentiality, parents were not explicitly informed about any of the selection variables of the study. On the day of the screening, students were given information on the screening, the ethical issues (confidentiality and the voluntary nature of participation), and the intervention. Parents and students provided active informed consent to participate in the intervention part of the study.

The study was approved by the Medical Ethical Commission for Mental Health (METIGG), i.e. the study was evaluated by the METIGG, which considered the study did not fall within the WMO Act (Medical Research Involving Human Subject Act). However, for the consent procedure, we adhered to the guidelines and recommendations of the METIGG. 


\section{Randomization}

After the screening and consent procedure was completed, the schools were randomized to one of the two conditions (experimental or control). This occurred at school and not class or individual level to avoid contamination between conditions. A randomization scheme was used, stratified by level of education provided by the school (only lower secondary education; only higher secondary education; both lower and higher secondary education) and, within these three strata, by school size (50\% largest schools; $50 \%$ smallest schools).

\section{Intervention}

\section{Intervention condition}

The intervention involved two group sessions, carried out at the participants' schools. The group sessions were tailored to one of the four personality profiles, so there were four different groups of two sessions each. Both group sessions lasted $90 \mathrm{~min}$ and were spread across two weeks. The intervention used student manuals. The original student manuals, developed in Canada, were translated and adapted to the Dutch cultural and school context. The theoretical basis of Preventure and the content of the intervention are described in the study protocol paper [23].

\section{Control condition}

Students assigned to the control group received no further intervention.

\section{Treatment integrity}

The intervention was provided by qualified counsellors and co-facilitators. The three counsellors and two co-facilitators attended a 2-day training session led by Dr P. J. Conrod and Dr N. Castellanos from King's College, London, who developed the original intervention. Furthermore, all counsellors had practiced the two group sessions at a pilot school with supervision and feedback. These supervised interventions were run with students from a pilot school, not recruited for the Preventure trial. Also, each counsellor's first two group sessions were observed by a supervisor who had participated in the Preventure training session. All the counsellors were provided with feedback during four peer reviewing meetings under the guidance of the same supervisor.

At the first workshop, $80 \%$ of participants were present, and at the second workshop $71 \%$. In total, $71 \%$ of the students attended both workshops. Students who did not attend both workshops were more likely to have recently been binge drinking (59\% vs. $45 \%)\left(X^{2}(1)=5.12\right.$, $\rho<.024)$ and were more likely to skip one or more of the follow-up measurements $\left(X^{2}(1)=25.87, \rho<.0001\right)$ than students who attended both workshops.

\section{Data collection}

The data were collected by means of an online questionnaire asking for demographics, personality risk profile, drinking behaviors, and outcomes. The data collection took place during a regular lesson (approximately $50 \mathrm{~min}$ ), and questionnaires were administered by a trained research assistant from the Trimbos Institute. The baseline/screening survey was collected 2-6 months before the intervention started. Students assigned to the experimental or control condition received the follow-up questionnaires at 2, 6, and 12 months after completion of the intervention period.

The response on the 2- (83\%), 6- (79\%), and 12-month (76\%) follow-up measurement was high. Those who only completed the screening questionnaire $(7 \%$ of all 699 respondents) were more likely to attend a lower-level educational school than those who completed at least one of the three follow-up questionnaires $(53 \%$ vs. $34 \%$, $\left.X^{2}(1)=8.20, \rho<.004\right)$.

\section{Measures}

\section{Outcomes}

Depression The level of depression was measured with the Dutch version of the widely used 20-item Centre for Epidemiological Studies Depression Scale (CES-D) [26]. The CES-D scale ranges from 0 to 60, with higher scores indicating a higher level of symptoms. Example items are, "During the last week, I felt hopeful about the future," "During the last week, I thought my life had been a failure." The measure showed a high internal consistency $(\alpha=0.80)$.

Anxiety The Childhood Anxiety Sensitivity Index (CASI) $[27,28]$ is a self-report questionnaire to assess children and adolescents' fear of anxiety symptoms. Silverman et al. [27] constructed the CASI as a developmentally sensitive version of the adult Anxiety Sensitivity Index [29] for younger test-takers. Respondents are asked to rate their degree of agreement with each of 18 items (e.g. "It scares me when I feel nervous") on a 3-point Likert scale ranging from 0 (none) to 2 (a lot). The CASI showed acceptable two-week test-retest reliability and good criterion-related validity in clinical and nonclinical samples of children and teens [30, 31]. The internal consistency in the present sample was high $(\alpha=0.87)$. 
Hyperactivity and conduct problems The Strengths and Difficulties Questionnaire (SDQ) [32] is a behavioral screening questionnaire measuring strengths and difficult behavior in adolescents. The SDQ yields five scale scores (emotional symptoms, conduct problems, hyperactivity, peer problems, and pro-social behavior), each consisting of five items and a scale score from 0 to 10 . The SDQ has been shown to be highly correlated with other well-established measurement instruments, including the Child Behavior Checklist [33]. In this study the conduct scale and the hyperactivity scale were used. The internal consistency of the hyperactivity scale was acceptable $(\alpha=0.68)$. As the instrument elicits information on the previous 6 months, hyperactivity was only assessed at 6 and 12 months post intervention. The internal consistency of the conduct problems scale was too low $(\alpha=0.50)$ and, therefore, it was decided not to use the data of this scale for further analyses.

Delinquent behavior To assess delinquent behavior, we used a 14-item self-report measure [34]. For each of the different types of delinquent behavior (e.g. shoplifting, stealing a bicycle or a moped, vandalizing a bus/train, carrying a knife or weapon), respondents were asked to indicate whether they had committed these offenses in the previous six months. A positive answer was scored a 1. By summing up the item scores, a total score was calculated, ranging from 0 to 14 . As the instrument elicits information on the previous six months, delinquent behavior was only assessed at 6 and 12 months post intervention.

\section{Screening}

Lifetime prevalence of alcohol use The lifetime prevalence of alcohol use was measured with information on the number of times respondents had used alcohol in their lives $[37,38]$. Those answering once or more were classified as alcohol users.

Personality risk profile The SURPS [25] consists of 23 non-overlapping items that assist in discriminating personality dimensions independent of substance use behavior. Items are scored on a 4-point scale, $1=$ strongly disagree, $2=$ disagree, $3=$ agree, $4=$ strongly agree. The personality dimension Negative Thinking (seven items) refers to hopelessness, which might lead to depressive symptoms. A sample item on the Negative Thinking subscale is "I feel that I'm a failure." The Anxiety Sensitivity dimension (five items) measures fear of bodily sensations. The Sensation Seeking subscale (six items) measures the tendency to seek out thrilling experiences, and the tendency to act without thinking is measured by the Impulsivity scale (five items). In the present study, for each of the four personality risk scales, respondents scoring at least one standard deviation above the sample mean were coded as 1 on the corresponding risk scale and all others were coded as 0 . Studies in both adolescent and adult samples in several countries, including the Netherlands, have shown that this scale has good internal reliability, good convergent and discriminant validity, and adequate testretest reliability $[14,15,25,35,36]$. The instrument has been successfully applied in the Netherlands [15]. In the present sample, the internal consistency of the subscales appeared to be adequate (NT: $\alpha=0.84$, AS: $\alpha=0.72$, IMP: $\alpha=0.69$, SS: $\alpha=0.66)$.

\section{Demographics}

A questionnaire assessing demographic information asked participants to report on their age, sex, and ethnic background. The child's ethnicity was determined by the mother's country of birth. If the mother was born in The Netherlands, the child's ethnicity was determined by the father's country of birth. The educational level was classified as low $=(1)$ including the three lowest levels of lower secondary professional education or high $=(0)$ including the highest level of lower secondary professional education or higher general secondary education or pre-university education.

\section{Recent binge drinking}

Recent binge drinking was defined as drinking at least five alcoholic drinks at one occasion in the last month [37, 38]. Those answering once or more were classified as recent binge drinkers.

\section{Power}

The sample size was based on the primary outcomes of this Preventure study; a reduction in the percentage of students engaging in binge drinking. The first step in that power calculation resulted in 183 students in each condition to test the hypothesis in a 2-sided test at alpha $=0.05$ and a power of $(1-$ beta $)=0.80$. Because of the loss of power due to randomization of schools and the increase in error because of applying a multiple imputation procedure to fill in missing values, 256 respondents per condition (intervention and control) needed to be included at baseline (see [23] for the full calculation). Simple post hoc analyses showed that with 183 students an effect size of 0.33 can be determined for the social emotional outcomes in a 2-sided test at alpha $=0.05$ and a power of $(1-$ beta $)=0.80$. This effect size represents a small to moderate effect size. The power was also expected to be sufficient to assess potential moderating effects of personality groups, as interaction effects were calculated on the total sample. 


\section{Statistical analyses}

The effects of Preventure in the intervention condition were tested using multivariate regression analyses in Mplus version 6.11 with the MLR estimator [39]. The analyses of interest were 'condition' and 'condition $\mathrm{x}$ personality risk group interaction' effects. The analyses result in standardized Beta coefficients, testing whether the 2-, 6-, and 12-month follow-up scores on outcomes varied as a function of the intervention within the full sample, and whether the follow-up scores on a specific outcome within a specific personality group varied as a function of the intervention (for example a reduction in depression score in the NT group).

As age, sex, educational level, and binge drinking were uneven distributed across the conditions, and as previous studies have showed that these variables are correlated to the development of our outcomes measures [40-42], all analyses were conducted with these variables as covariates to control for any possible bias stemming from the imbalance. However, following De Boer et al. [43] we will also present the unadjusted analyses, i.e. with only the baseline measure of the outcome variable as a covariate in the model.

By means of a latent-growth curve approach, post hoc analyses were conducted to examine the effect of the Dutch version of Preventure on the linear increase on the outcomes variables. As three follow-up measures is seen as a minimum to perform this type of analysis, we can only show the results for depression and anxiety. A latentgrowth model approaches the analysis of repeated measures from the perspective of an individual growth curve for each subject; each growth curve has a certain initial level (intercept) and a certain rate of change over time (slope) [44]. In this study the outcome slope was regressed on the Preventure intervention condition variable controlling for the outcome measure intercept. Again both adjusted and unadjusted analyses were conducted. The fit of the models was assessed by the following fit indexes: $\chi^{2}$, comparative fit index (CFI), Tucker-Lewis index (TLI), and root mean square error of approximation (RMSEA). Due to the sensitivity of the $\chi^{2}$ goodness-of-fit test to sample sizes, the fit indices CFI, TLI, and RMSEA were used. Except for the values of RMSEA (which would be satisfactory if smaller

Table 1 Socio-demographics of intervention and control condition

\begin{tabular}{lll}
\hline & Intervention condition & Control condition \\
\hline Male & $47 \%$ & $57 \%$ \\
Age & 13.9 years $(\mathrm{SD}=0.98)$ & $14.1(\mathrm{SD}=0.77)$ \\
Dutch & $87 \%$ & $87 \%$ \\
Low level of education & $43 \%$ & $26 \%$ \\
Binge drinking & $49 \%$ & $37 \%$ \\
\hline
\end{tabular}

than 0.08), goodness-of-fit values greater than 0.90 are considered an acceptable fit [45].

Missing observations at follow-up were imputed using multiple regression imputation as implemented in Mplus 6.11. To correct for non-independence because of clustering of the data, the TYPE = COMPLEX procedure in Mplus was used. Following Schulz and Grimes [46] the level of statistical significance was set at $\rho<0.05$, and no Bonferroni correction was applied. In order to assess the influence of workshop retention, we ran all analyses on a dataset including only students who attended both workshops.

\section{Results}

\section{Baseline}

Table 1 shows the distribution of gender, age, ethnicity, educational level, and recent binge drinking in both the intervention and control condition. Tables 2 and 3 show the means and standard deviations of the outcome variables for the total sample and for each of the four personality groups, separately. There were no significant baseline differences between the two conditions on any of the outcome variables.

\section{Intervention effects for the total high risk sample}

We first tested main condition effects in the overall high risk sample. No significant differences were found between the intervention and control condition on any of the outcome variables (see Table 4).

\section{Intervention effects per personality group}

Second, we tested condition effects in specific personality groups. Table 5 shows the Beta coefficients of fourteen tests, testing intervention effectiveness on specific outcomes within specific personality groups. For depression in the NT group, a significant effect was found at 12-month follow-up. The descriptive results (Table 3) suggest that, although depressive feelings were reduced in both the intervention and the control group, the effect was stronger in the control group. Tables 3 and 5 also show that, as hypothesized, a stronger reduction of anxiety sensitivity scores was found in the AS intervention group than in the control condition at 12-month follow-up.

\section{Post hoc analyses}

Post-hoc analyses were conducted, by means of a latentgrowth curve approach, to examine the effect of Preventure on a linear increase in the outcome variables. 
Table 2 Baseline and follow-up levels of outcomes for the total sample

\begin{tabular}{|c|c|c|c|}
\hline & & $\begin{array}{l}\text { Intervention condition } \\
\text { Mean (SD) }\end{array}$ & $\begin{array}{l}\text { Control condition } \\
\text { Mean (SD) }\end{array}$ \\
\hline \multirow{4}{*}{$\begin{array}{l}\text { Depression } \\
\text { (range 0-60) }\end{array}$} & Baseline & $16.55(7.84)$ & $16.44(7.90)$ \\
\hline & 2 months & $14.76(6.70)$ & $14.91(6.68)$ \\
\hline & 6 months & $14.79(7.55)$ & $14.46(6.66)$ \\
\hline & 12 months & $15.98(8.71)$ & $14.94(6.98)$ \\
\hline \multirow{4}{*}{$\begin{array}{l}\text { Anxiety } \\
\text { (range 0-36) }\end{array}$} & Baseline & $7.83(6.29)$ & $7.85(5.81)$ \\
\hline & 2 months & $6.88(6.19)$ & $6.98(5.41)$ \\
\hline & 6 months & $6.50(6.07)$ & $6.62(5.67)$ \\
\hline & 12 months & $6.54(6.40)$ & $6.84(5.96)$ \\
\hline \multirow{3}{*}{$\begin{array}{l}\text { Hyperactivity } \\
\text { (range 0-10) }\end{array}$} & Baseline & $5.56(2.32)$ & $5.31(2.21)$ \\
\hline & 6 months & $5.36(2.29)$ & $5.12(2.34)$ \\
\hline & 12 months & $5.30(2.44)$ & $5.15(2.36)$ \\
\hline \multirow{3}{*}{$\begin{array}{l}\text { Delinquency }{ }^{\mathrm{a}} \\
\text { (range 0-14) }\end{array}$} & Baseline & $2.18(2.28)$ & $1.85(2.07)$ \\
\hline & 6 months & $2.42(2.86)$ & $2.45(2.93)$ \\
\hline & 12 months & $2.39(3.13)$ & $2.28(2.87)$ \\
\hline
\end{tabular}

${ }^{a}$ Hyperactivity and delinquent behavior were only assessed at 6 and 12 months post intervention because the measurement instrument elicits six-monthly information

Table 3 Baseline and follow-up levels of outcomes for the four risk profiles

\begin{tabular}{|c|c|c|c|}
\hline & & $\begin{array}{l}\text { Intervention condition } \\
\text { Mean (SD) }\end{array}$ & $\begin{array}{l}\text { Control condition } \\
\text { Mean (SD) }\end{array}$ \\
\hline \multirow{4}{*}{$\begin{array}{l}\text { Depression } \\
\text { (range 0-60) } \\
\text { (NT only) }\end{array}$} & Baseline & $22.16(9.70)$ & $22.04(8.64)$ \\
\hline & 2 months & $17.25(7.08)$ & $17.61(7.09)$ \\
\hline & 6 months & $16.23(7.48)$ & $16.24(7.42)$ \\
\hline & 12 months & $18.44(9.01)$ & $15.48(6.94)$ \\
\hline \multirow{4}{*}{$\begin{array}{l}\text { Anxiety } \\
\text { (range } 0-36) \\
\text { (AS only) }\end{array}$} & Baseline & $12.02(6.32)$ & $12.82(6.48)$ \\
\hline & 2 months & $9.66(7.24)$ & $10.38(6.02)$ \\
\hline & 6 months & $8.70(6.82)$ & $10.54(5.55)$ \\
\hline & 12 months & $7.90(6.57)$ & $10.89(7.24)$ \\
\hline \multirow{3}{*}{$\begin{array}{l}\text { Hyperactivity } \\
\text { (range } 0-10) \\
\text { (IMP only) }\end{array}$} & Baseline & $6.54(2.17)$ & $6.31(2.12)$ \\
\hline & 6 months & $5.97(2.13)$ & $5.86(2.13)$ \\
\hline & 12 months & $5.81(2.18)$ & $5.78(2.14)$ \\
\hline \multirow{3}{*}{$\begin{array}{l}\text { Hyperactivity } \\
\text { (range } 0-10 \text { ) } \\
\text { (SS only) }\end{array}$} & Baseline & $5.36(2.12)$ & $4.93(2.17)$ \\
\hline & 6 months & $5.51(2.20)$ & $4.82(2.37)$ \\
\hline & 12 months & $5.29(2.45)$ & $4.98(2.36)$ \\
\hline \multirow{3}{*}{$\begin{array}{l}\text { Delinquency } \\
\text { (range } 0-14 \text { ) } \\
\text { (IMP only) }\end{array}$} & Baseline & $2.54(2.37)$ & $2.21(2.21)$ \\
\hline & 6 months & $2.96(3.22)$ & $2.61(2.65)$ \\
\hline & 12 months & $2.95(3.46)$ & $2.74(3.36)$ \\
\hline \multirow{3}{*}{$\begin{array}{l}\text { Delinquency } \\
\text { (range } 0-14 \text { ) } \\
\text { (SS only) }\end{array}$} & Baseline & $2.41(2.28)$ & $2.12(2.00)$ \\
\hline & 6 months & $2.92(2.76)$ & $2.96(3.12)$ \\
\hline & 12 months & $2.55(3.04)$ & $2.68(2.78)$ \\
\hline
\end{tabular}

In this model, the slope of the outcome was regressed on the Preventure intervention variable. The fit between the linear model and the data was excellent for both depression $\left[n=699 ; \chi^{2}=19.246(\mathrm{~d} f=4), \rho<0.001\right.$; RMSEA $=0.072$, CFI $=0.959$, TLI $=0.939]$, and anxiety $\left[n=699 ; \chi^{2}=6.361(\mathrm{~d} f=4), \rho<0.10 ; \mathrm{RMSEA}=0.029\right.$, $\mathrm{CFI}=0.997$, TLI $=0.995]$. The intercepts and slopes were significant for both depression $\left(\beta_{0}=2.91, \rho<0.001\right.$ and $\left.\beta_{1}=-0.31, \rho<0.001\right)$ and anxiety $\left(\beta_{0}=7.73, \rho<0.001\right.$ and $\left.\beta_{1}=-0.63, \rho<0.001\right)$, indicating that the participants scored greater than zero on the outcomes at baseline and that the levels of depression and anxiety decreased over time. A quadratic trend was also tested, but this resulted in a non-fitted model and, therefore, omitted. No significant intervention effects were found for both outcome measures, nor for the full sample analyses, nor for the specific risk profile samples.

\section{Per protocol analyses}

Given that a substantial proportion of the respondents in the intervention condition did not attend one (29\%) or both $(20 \%)$ workshops, we reran all analyses on a sample including all students in the control condition and only those students in the experimental group who attended both workshops $(71 \%, n=242)$. These analyses showed similar results, with one exception. We found a significant negative effect $(\beta=0.107, \rho=0.045)$ in delinquent behavior in the IMP group at 6-month follow-up, but only in the fully adjusted model and not in the unadjusted model.

\section{Discussion}

The aim of this study was to test the effectiveness of Preventure in the Netherlands on a range of mental health and conduct problems at 2, 6, and 12 months post intervention. We tested for a reduction in depression, anxiety, and hyperactivity rates and delinquent risk taking behavior in the total experimental group as compared to the control group and expected these effects to be moderated by personality. Only one out of the fourteen hypotheses was supported; we found a positive intervention effect on anxiety rates in the AS group at 12-month follow-up. Contrary to our hypothesis, a negative intervention effect on depression rates was found at 12-month follow-up in the NT group. These significant effects were not found in the post hoc growth curve analyses. Notwithstanding the intervention effects on psychological problems found in a previous study of Preventure [9], as well as the teacher-delivered variant of Preventure, our results suggest that the effects 
Table 4 Effect of Preventure on depression, anxiety, hyperactivity, and delinquency within the total sample

\begin{tabular}{llllll}
\hline & & $\beta^{\mathrm{a}}(95 \% \mathrm{CI})$ & $P$ & $\beta^{\mathrm{b}}(95 \% \mathrm{CI})$ & $P$ \\
\hline Depression & 2 months & $-0.021(-0.09,0.05)$ & 0.54 & $-0.014(-0.09,0.06)$ & 0.70 \\
& 6 months & $0.016(-0.06,0.09)$ & 0.69 & $0.021(-0.09,0.13)$ & 0.71 \\
Anxiety & 12 months & $0.048(-0.04,0.13)$ & 0.27 & $0.064(-0.05,0.18)$ & 0.26 \\
& 2 months & $-0.008(-0.09,0.07)$ & 0.84 & $-0.007(-0.10,0.09)$ & 0.89 \\
Hyperactivity & 6 months & $-0.011(-0.09,0.07)$ & 0.79 & $-0.014(-0.10,0.07)$ & 0.76 \\
& 12 months & $-0.024(-0.11,0.07)$ & 0.60 & $-0.024(-0.12,0.07)$ & 0.63 \\
Delinquency & 6 months & $0.015(-0.06,0.09)$ & 0.69 & $0.020(-0.05,0.09)$ & 0.59 \\
& 12 months & $-0.006(-0.08,0.06)$ & 0.86 & $0.005(-0.05,0.09)$ & 0.87 \\
& 6 months & $-0.040(-0.15,0.07)$ & 0.47 & $-0.039(-0.15,0.07)$ & 0.48 \\
& 12 months & $-0.015(-0.11,0.08)$ & 0.74 & $-0.017(-0.11,0.07)$ & 0.71 \\
\hline
\end{tabular}

$\beta=$ Standardized logistic regression coefficient

a Adjusted for sex, age, education, and binge drinking

${ }^{\mathrm{b}}$ Unadjusted for sex, age, education, and binge drinking

\begin{tabular}{llllll}
\hline & $\beta^{\mathrm{a}}(95 \% \mathrm{CI})$ & $P$ & $\beta^{\mathrm{b}}(95 \% \mathrm{CI})$ & $P$ \\
\hline Depression & 2 months & $-0.014(-0.14,0.11)$ & 0.83 & $-0.014(-0.14,0.11)$ & 0.82 \\
(NT only) & 6 months & $-0.031(-0.14,0.08)$ & 0.58 & $-0.024(-0.13,0.08)$ & 0.66 \\
& 12 months & $0.116(0.01,0.22)$ & $0.04^{*}$ & $0.115(0.01,0.22)$ & $0.04^{*}$ \\
Anxiety & 2 months & $-0.012(-0.13,0.11)$ & 0.84 & $-0.012(-0.14,0.11)$ & 0.85 \\
(AS only) & 6 months & $-0.076(-0.19,0.04)$ & 0.20 & $-0.077(-0.19,0.04)$ & 0.20 \\
& 12 months & $-0.128(-0.25,0.00)$ & $0.05^{*}$ & $-0.133(-0.26,-0.01)$ & $0.04^{*}$ \\
Hyperactivity & 6 months & $-0.021(-0.12,0.08)$ & 0.70 & $-0.022(-0.12,0.08)$ & 0.66 \\
(IMP only) & 12 months & $-0.020(-0.14,0.10)$ & 0.75 & $-0.022(-0.15,0.11)$ & 0.73 \\
Hyperactivity & 6 months & $0.073(-0.05,0.19)$ & 0.24 & $-0.071(-0.05,0.19)$ & 0.25 \\
(SS only) & 12 months & $0.011(-0.10,0.12)$ & 0.85 & $0.010(-0.10,0.12)$ & 0.85 \\
Delinquency & 6 months & $0.066(-0.05,0.18)$ & 0.27 & $0.055(-0.07,0.18)$ & 0.39 \\
(IMP only) & 12 months & $0.022(-0.11,0.15)$ & 0.75 & $0.013(-0.12,0.15)$ & 0.85 \\
Delinquency & 6 months & $-0.005(-0.14,0.13)$ & 0.94 & $-0.003(-0.14,0.13)$ & 0.98 \\
(SS only) & 12 months & $-0.036(-0.12,0.05)$ & 0.42 & $-0.036(-0.12,0.05)$ & 0.42 \\
\hline
\end{tabular}

$\beta=$ Standardized logistic regression coefficient)

a Adjusted for sex, age, education, and binge drinking

${ }^{\mathrm{b}}$ Unadjusted for sex, age, education, and binge drinking of Dutch-Preventure on psychological problems are limited. We will discuss some possible explanations for our findings.

First, although overall effects on depression outcomes were found in the Adventure trial, the study did not identify any personality-specific effects on anxiety and depression. The authors suggest that an increased intervention dose may be needed for these specific subgroups [10]. Moreover, the literature suggests that effective interventions for internalizing and externalizing problem behavior are, mostly, multi-year programs, focusing on at-risk groups, targeting risk and protective factors, and focusing on multiple domains, i.e. school, home environment, and children as well [47]. Although Preventure also focuses on at-risk groups and targets risk and protective factors, it is also a very brief and single-domain intervention. A more extended and multi-domain version of Preventure could probably enhance its effectiveness on mental health outcomes. However, this would make the intervention more expensive. Moreover, it could make the intervention less attractive for schools to implement as it becomes more intensive and complex and, therefore, more time consuming, which may interfere too much with the day-to-day running of the school.

Second, the prevalence of delinquency in our sample appeared to be low. Consequently, it may be that this study was underpowered to detect intervention effects on this outcome measure. 
Third, interventions that have proven to be effective in the original context are for a variety of reasons not always effective outside this context. Sample differences, other ways of delivering the intervention, cultural differences and many other factors can influence the outcomes of preventive interventions $[48,49]$.

\section{Strengths and limitations}

A strength of this study is that the outcomes were measured at 2, 6, and 12 months. Intervention effects could, therefore, be tested shortly after implementation, as well as a full year later. A limitation in this study is that the fidelity of the implementation was not monitored by means of thorough measurements. Although the counselors received their training directly from the intervention developers, and had observation and feedback sessions, it cannot not be ruled out that the implementation quality was not as high as during the other Preventure studies. Another limitation is that the use of self-reports might have led to measurement errors, due to situational and cognitive influences [50]. To overcome situational influences (e.g. social desirability) and to optimize measurement validity, we guaranteed full confidentiality (anonymity) to our participants [51, 52].

\section{Conclusion}

In conclusion, in the ongoing search for effective schoolbased health promotion interventions that are brief and target multiple problems, Preventure appears to be effective in the prevention of substance use problems, yet this study found no evidence for its effectiveness on other mental health problems. Thereby, this study demonstrates the importance of replication studies. Although much can be learned from interventions that were developed and studied abroad, it cannot be assumed that positive intervention effects found in one study will also be found in studies performed in other (cultural) contexts and under other circumstances. However, the personality-targeted prevention approach is quite novel and promising. Many school-based interventions suffer from severe implementation problems because of the length of the program, which in turn affects their effectiveness [53], and it is, therefore, worth continuing to search for interventions that are very short, simple, targeted, and effective.

\section{Compliance with ethical standards}

Conflicts of interest J.L., F.G., M.K., R.W. and R.E. declare that they have no conflict of interest. PC is the developer and licensee of Preventure.

\section{References}

1. De Graaf R, Bijl RV, Smit F, Vollebergh WAM, Spijker J (2002) Risk factors for 12-month comorbidity of mood, anxiety, and substance use disorders: findings from the Netherlands Mental Health Survey and Incidence Study. Am J Psychiatry 156:620-629

2. Kessler RC (2004) Impact of substance abuse on the diagnosis, course, and treatment of mood disorders. The epidemiology of dual diagnosis. Biol Psychiatry 56(10):730-737

3. Kendler KS, Prescott CA, Myers J, Neale MC (2003) The structure of genetic and environmental risk factors for common psychiatric and substance use disorders in men and women. Arch Gen Psychiatry 60(9):929-937

4. Conrod PJ, Stewart SH, Comeau MN, Maclean AM (2006) Efficacy of cognitive-behavioral interventions targeting personality risk factors for youth alcohol misuse. J Clin Child Adolesc Psychol 35(4):490-504

5. Conrod PJ, Castellanos N, Mackie C (2008) Personality-targeted interventions delay the growth of adolescent drinking and binge drinking. J Child Psychol Psychiatry 49(2):181-190

6. Conrod PJ, Castellanos-Ryan N, Mackie C (2011) Long-term effects of a personality-targeted intervention to reduce alcohol use in adolescents. J Consult Clin Psychol 79(3):296-306

7. O'Leary-Barrett M, Mackie CJ, Castellanos-Ryan N, Al-Khudhairy N, Conrod PJ (2010) Personality-targeted interventions delay uptake of drinking and decrease risk of alcohol-related problems when delivered by teachers. J Am Acad Child Adolesc Psychiatry 49(9):954-963

8. Conrod PJ, Castellanos-Ryan N, Strang J (2010) Brief, personality-targeted coping skills interventions and survival as a nondrug user over a 2-year period during adolescence. Arch Gen Psychiatry 67(1):85-93

9. Castellanos N, Conrod PJ (2006) Brief interventions targeting personality risk factors for adolescent substance misuse reduce depression, panic and risk-taking behaviours. J Mental Health 15(6):645-658

10. O'Leary-Barrett M, Topper L, Al-Khudairy N, Pihl RO, Castellanos-Ryan N, Mackie CJ, Conrod PJ (2013) Two-year Impact of personality-targeted, teacher-delivered interventions on youth internalizing and externalizing problems: a cluster-randomized trial. J Am Acad Child Adolesc Psychiatry 52(9):911-920

11. Comeau N, Stewart SH, Loba P (2001) The relations of trait anxiety, anxiety-sensitivity, and sensation seeking to adolescents' motivations for alcohol, cigarette, and marijuana use. Addict Behav 26:1-24

12. Cooper ML, Frone MR, Russell M, Mudar P (1995) Drinking to regulate positive and negative emotions: a motivational model of alcohol use. J Pers Soc Psychol 69:990-1005

13. Blackwell E, Conrod PJ, Hansen N (2002) Negative cognitions, hopelessness, and depression related drinking motives. Abstract in alcoholism: clinical and experimental research, 26(Supplement), 27A. Poster session presented at the Scientific Meeting of the Research Society on Alcoholism, San Francisco, CA

14. Conrod PJ, Woicik P (2002) Validation of a four factor model of personality risk for substance abuse and examination of a brief instrument for assessing personality risk. Addict Biol 7:329-346

15. Malmberg M, Overbeek G, Monshouwer K, Lammers J, Vollebergh WAM, Engels RCME (2010) Substance use risk profiles and associations with early substance use in adolescence. J Behav Med 33:474-485

16. Pulkkinen L, Pitkänen T (1994) A prospective study of the precursors to problem drinking in young adulthood. J Stud Alcohol $55: 578-587$ 
17. Shall M, Kemeny A, Maltzman I (1992) Factors associated with alcohol use in university students. J Stud Alcohol 53:122-136

18. Stewart SH, Peterson JB, Pihl RO (1995) Anxiety sensitivity and self-reported alcohol consumption rates in university women. J Anxiety Disord 9:283-292

19. Joiner TE $\mathrm{Jr}$ (2000) A test of hopelessness theory in youth psychiatric inpatients. J Clin Child Psychol 29:167-176

20. Maller RG, Reiss S (1992) Anxiety sensitivity in 1984 and panic attacks in 1987. J Anxiety Disord 6:241-247

21. Moeller FG, Barratt ES, Dougherty DM, Schmitz JM, Swann AC (2001) Psychiatric aspects of impulsivity. Am J Psychiatry 158:1783-1793

22. Arnett JJ (1994) Sensation seeking: a new conceptualization and a new scale. Personal Individ Differ 16:289-296

23. Lammers J, Goossens F, Lokman S, Monshouwer K, Lemmers L, Conrod P, Kleinjan M (2011) Evaluating a selective prevention programme for binge drinking among young adolescents: study protocol of a randomized controlled trial. BMC Public Health 11:126. doi:10.1186/1471-2458-11-126

24. Lammers J, Goossens F, Conrod P, Engels R, Wiers RW, Kleinjan M (2015) Effectiveness of a selective intervention program targeting personality risk factors for alcohol misuse among young adolescents: results of a cluster randomized controlled trial. Addiction 110:1101-1109

25. Woicik PA, Stewart SH, Pihl RO, Conrod PJ (2009) The substance use risk profile scale: a scale measuring traits linked to reinforcement-specific substance use profiles. Addict Behav 34:1042-1055

26. Bouma J, Ranchor AV, Sanderman R, Van Sonderen E (1995) Het meten van symptomen van depressie met de CES-D: een handleiding. [Measuring symptoms of depression with the CESD: Manual]. Groningen: Rijksuniversiteit Groningen

27. Silverman WK, Fleisig W, Rabian B, Peterson RA (1991) Childhood anxiety sensitivity index. J Clin Child Psychol 20:162-168

28. Van Widenfelt BM, Siebelink BM, Goedhart A, Treffers DA (2002) The Dutch childhood anxiety sensitivity index: psychometric properties and factor structure. J Clin Child Psychol 31(1):90-100

29. Reiss SR, Peterson R, Gursky D, McNally R (1986) Anxiety sensitivity, anxiety frequency and the prediction of fearfulness. Behav Res Ther 24:11-18

30. Walsh TM, Stewart SH, McLaughlin E, Comeau MN (2004) Gender differences in childhood anxiety sensitivity index dimensions. J Anxiety Disord 18:695-706

31. Weems CF, Hammond-Laurence K, Silverman WK, Ginsburg GS (1998) Testing the utility of the anxiety sensitivity construct in children and adolescents referred for anxiety disorders. J Clin Child Psychol 27:69-77

32. Goodman R (1997) The strengths and difficulties questionnaire: a research note. J Child Psychol Psychiatry 38(5):581-586

33. Goodman R, Scott S (1999) Comparing the strengths and difficulties questionnaire and the child behavior checklist: is small beautiful? J Abnorm Child Psychol 27(1):17-24

34. Baerveldt C (1992) Schools and the prevention of petty crime: search for a missing link. J Quant Criminol 8:79-94

35. Krank M, Stewart SH, Wall A-M, Woicik PB, Conrod PJ (2011) Structural, concurrent, and predictive validity of the substance use risk personality scale in early adolescence. Addict Behav 36:37-46

36. Wiers RW, Ames SL, Hofmann W, Krank M, Stacey AW (2010) Impulsivity, impulsive and reflective processes and the development of alcohol use and misuse in adolescents and young adults. Front Psychol 1:144. doi:10.3389/fpsyg.2010.00144 Epub 2010 Sep 30

37. Hibell B, Guttormsson U, Ahlström S, Balakireva O, Bjarnason T, Kokkevi A, Kraus L (2009) The 2007 ESPAD report. Substance use among students in 35 European countries. Stockholm: The Swedish Council for Information on Alcohol and Other Drugs (CAN)

38. O'Malley PM, Bachman JG, Johnston LD (1983) Reliability and consistency in self-reports of drug use. Int J Addict 18:805-824

39. Muthén B, Muthén L (1998-2010) Mplus user's guide (6th ed.). Los Angeles, CA: Muthén \& Muthén. www.statmodel.com

40. Monshouwer K, Smit F, Ruiter M, Ormel J, Verhulst FC, Vollebergh WAM, Oldehinkel AJ (2012) Identifying target groups for the prevention of depression in early adolescence: the TRAILS study. J Affect Disord 138:287-294

41. Odgers CL, Moffitt TE, Broadbent JM, Dickson N, Hancox RJ, Harrington $\mathrm{H}$ et al (2008) Female and male antisocial trajectories: from childhood origins to adult outcomes. Dev Psychopathol 20:673-716

42. Moffitt TE, Caspi A (2001) Childhood predictors differentiate life-course persistent and adolescence-limited antisocial pathways among males and females. Dev Psychopathol 13:355-375

43. De Boer MR, Waterlander WE, Kuijper LDJ, Steenhuis IHM, Twisk JWR (2015) Testing for baseline differences in randomized controlled trials: an unhealthy research behavior that is hard to eradicate. In J Behav Nutr Phys Activity 12:4

44. Duncan TE, Duncan SC, Strycker LA, Li F, Alpert A (1999) An introduction to latent variable growth curve modeling: concepts, issues, and applications. Erlbaum, Mahwah

45. Bentler PM, Bonett DG (1980) Goodness-of-fit procedures for the evaluation and selection of log-linear models. Psychol Bull 88:588-606

46. Schulz KF, Grimes DA (2005) Multiplicity in randomized trials I: endpoints and treatments. Lancet 365:1591-1595

47. Greenberg MT (2000) Preventing mental disorders in school-age children. A review of the effectiveness of prevention programs. Prevention Research Center for the Promotion of Human Development College of Health and Human Development Pennsylvania State University

48. Eisner M (2009) No effects in independent prevention trials: can we reject the cynical view? J Exp Criminol 5:163-183

49. Flay BR, Biglan A, Boruch RF, Castro FG, Gottfredson D, Kellam S, Mocicki EK, Schinke S, Valentine JC, Ji P (2005) Standards of Evidence: criteria for efficacy, effectiveness and dissemination. Prev Sci 6:151-175

50. Brener ND, Billy JO, Grady WR (2003) Assessment of factors affecting the validity of self-reported health-risk behavior among adolescents: evidence from the scientific literature. J Adolesc Health 33:436-457

51. Koning IM, Vollebergh WAM, Smit F, Verdurmen JEE, van der Eijnden RJJM, ter Bogt TFM et al (2009) Preventing heavy alcohol use in adolescents (PAS): cluster randomized trial of a parent and student intervention offered separately and simultaneously. Addiction 104:1669-1678

52. Del Boca FK, Darkes J (2003) The validity of self-reports of alcohol consumption: state of the science and challenges for research. Addiction 98:1-12

53. Elliot SE, Mihalic S (2004) Issues in disseminating and replicating effective prevention programs. Prev Sci 5(1):47-53 